\title{
Facilitating and inhibiting factors in change processes based on the lean tool 'value stream mapping': an exploratory case study at hospital wards
}

Winkel, Jørgen; Edwards, Kasper; Birgisdóttir, Birna Dröfn; Gunnarsdóttir, Sigrún

Published in:

International Journal of Human Factors and Ergonomics

Publication date:

2015

Document Version

Peer reviewed version

Link back to DTU Orbit

Citation (APA):

Winkel, J., Edwards, K., Birgisdóttir, B. D., \& Gunnarsdóttir, S. (2015). Facilitating and inhibiting factors in change processes based on the lean tool 'value stream mapping': an exploratory case study at hospital wards. International Journal of Human Factors and Ergonomics, 3(3/4), 291-302.

\section{General rights}

Copyright and moral rights for the publications made accessible in the public portal are retained by the authors and/or other copyright owners and it is a condition of accessing publications that users recognise and abide by the legal requirements associated with these rights.

- Users may download and print one copy of any publication from the public portal for the purpose of private study or research.

- You may not further distribute the material or use it for any profit-making activity or commercial gain

- You may freely distribute the URL identifying the publication in the public portal 


\title{
Facilitating and inhibiting factors in change processes
}

\section{based on the Lean tool "Value Stream Mapping”}

\author{
An exploratory case study at hospital wards
}

*Jörgen WINKEL ${ }^{1,2}$, Kasper EDWARDS², Birna Dröfn BIRGISDÓTTIR ${ }^{3}$, Sigrún GUNNARSDÓTTIR

${ }^{1}$ University of Gothenburg, Dept. Sociology and Work Science, Box 705, SE-405 30

Gothenburg, Sweden;

${ }^{2}$ Technical University of Denmark, Dept. Management Engineering, Denmark;

${ }^{3}$ Reykjavik University, School of Business, Iceland;

${ }^{4}$ University of Iceland and Bifröst University, School of Business, Iceland;

*Corresponding author 


\section{Abstract:}

"Lean production” has become a prevalent rationalization methodology in healthcare. Value Stream Mapping (VSM) is a commonly used Lean tool to identify non-Value-AddingWork. VSM is a participatory tool. Thus it may offer an opportunity to combine interventions for improved performance and ergonomics. The aim of the present exploratory study is to report observations that seem to play significant roles as inhibitors and facilitators for proper intervention processes when using VSM.

Seven hospital wards have been investigated in Denmark, Iceland and Sweden. Information was obtained by screening key hospital documents and interviewing participants in and around the VSM processes. Nine tape-recorded interviews were performed.

The results tentatively point to the facilitating effect on the VSM process by emphasizing involvement and decision-making among the participants, $1^{\text {st }}$ line manager support and engagement, allocation of sufficient resources, work environment issues as part of the VSM methodology and VSM routines that are well-established and broadly accepted. 


\section{Introduction}

During recent years “Lean production” has become a prevalent rationalization methodology in healthcare. One commonly applied Lean tool is Value Stream Mapping (VSM). It is used to identify non-Value-Adding-Work (non-VAW, i.e. “waste”) in e.g. patient flows (Keyte and Locher, 2004). Waste/nonVAW is defined as the part of the overall processing time that is spent by the employees in actions not creating value as perceived by the customer (Liker, 2004). VSM is a participative paper-and-pen tool performed in workshops by the employees. Initially a “current state map” is made. A list of proposals of how to reduce waste is then produced. Feasible ideas are included in a "future state map" in which non-VAW has been minimized according to the Lean production strategy. Finally, an Action Plan is established based on the future state map.

Several previous studies have consistently showed that nonVAW most often offers less risky exposures compared to VAW (Kazmierczak et al., 2005; Ostenvik et al., 2008; Jonker et al., 2011; Jonker et al., 2013; Palmerud et al., 2012). A reduction of the amount of nonVAW may thus potentially cause impaired physical and psychosocial working conditions, i.e. "work intensification”, as frequently discussed in the scientific literature (for references see Westgaard and Winkel, 2011). Accordingly, Lean is often perceived as a "threat" by employees at hospitals (Härenstam et al., 2000, Personal Communications). However, previous research suggests that the VSM process may be catalyzed by including work environment issues (Jarebrant et al, 2015).

Recently, an ergonomic module to VSM (ErgoVSM) has been developed for the healthcare sector (Jarebrant et al., 2014). ErgoVSM aims at assisting the users to consider also physical and psychosocial implications of the suggested interventions. The ErgoVSM tool is now evaluated in a Nordic Multicentre Study at several hospitals in Denmark, Iceland and 
Sweden (Winkel et al., 2012, full paper not yet published). In that study we observed that the willingness to participate in the ordinary VSM workshops differed considerably between the investigated hospitals. Specific contextual factors seemed to account for these differences. Earlier research in this field shows that numerous contextual factors may strongly affect the outcome of Lean change programs (e.g. Brännmark et al., 2012). A systematic review of Rivilis et al (2008) showed evidence of the effectiveness of participatory ergonomic interventions on health outcomes. This may to be due to the ownership to the proposed changes obtained by the participatory process (e.g. Westgaard and Winkel, 1997). Haines and colleagues (2002) proposed and validated nine dimensions of participative ergonomics and assessed five of these as particularly important: “decision-making”, "mix of participants”, “remit”, “role of ergonomics specialist” and “involvement”.

Thus, there may be many reasons for differences in willingness to participate in ordinary VSM workshops. On this background the aim of the present exploratory case study is to get further insight into potential facilitating and inhibiting factors.

\section{Material and Methods}

\subsection{Investigated hospitals}

The overall methodological approach was a comparative study of VSM processes at seven hospital wards in three Nordic countries; three in Sweden, one in Iceland and three in Denmark, all included in the above mentioned Multicentre Study (Winkel et al., 2012). The hospitals were not organizationally connected and had developed distinctly different VSM methodologies. Two wards decided not to fulfil the VSM process, one in Iceland and one in Sweden.

\subsection{Methods}

Context information was obtained by screening available key hospital documents 
regarding decisions on introduction of Lean, aims and procedures. Researchers participated in the VSM workshops during which they made field notes.

Nine in-depth interviews, each lasting 20-40 minutes, were carried out. The informants were:

- Sweden:

o A production developer at the hospital

o The Lean coach of the workshops

o The $1^{\text {st }}$ line manager at the ward that decided to stop the VSM process

o One participant in the VSM workshop (a physician) at the ward that decided to stop the VSM process

- Iceland:

o The Lean coach of the VSM workshop

o The two $1^{\text {st }}$ line managers at the ward that decided to stop the VSM process (a physician and a nurse)

- Denmark

o The Lean Manager at the hospital

o The Lean coach of the VSM workshops

Our semi-structured topic guide for the interviews covered themes related to the study questions: (i) Previous experience of VSM and Lean (individual/at the ward/at the hospital); (ii) Who takes in general the initiative to perform VSM and selects what value stream to analyze; (iii) Aims of performing VSM; (iv) Facilitating and inhibiting factors of the workshop process.

\subsection{Data analyses}

The interviews were either transcribed or the interviewer made a short written summary including key statements followed by validation by the respondent. The data was first 
analysed with reference to the five factors identified as particularly important in participatory ergonomics by Haines et al (2002). The themes were then analysed inductively.

\section{Results}

\section{The Swedish wards:}

The investigated Swedish hospital had about 4300 employees and a turnover of about 370 million $€$ per year. In 2006 top management at the hospital decided to deploy Lean (Lifvergren, 2010). This became a significant part of a more comprehensive strategy with a declared strong focus on efficiency and costs.

Internal documents from the hospital year 2013 indicated that “... (the hospital) has decreased number of employees by $80, \ldots ”$. At the same time it was assessed that the production data indicated improvements compared to the previous year. But it was also communicated in internal reports that “... (the hospital) has not achieved the goal of a balanced budget”. Therefore it was decided that “...6,5 million $€$ will be identified in the processes ...” and “ ... the economic issue comprising 27-33 million $€$ should be solved in a few years".

One of the three investigated wards (ward 3 below) did not complete their VSM workshops while the other two did. Action Plans were generally developed by other stakeholders in the Lean organisation who made the decisions regarding implementation.

- Ward 1: "Proposals were suggested but not recorded”; "In summary, the method did not work fully, because the group did not manage to create a Future State that was better than the Current State” (Lean coach).

- Ward 2: “Frequent disturbances for all professions. Must constantly prioritize ordinary work"; "physician and $1^{\text {st }}$ line manager most active (during the 
workshops), other silent”; “ $1{ }^{\text {st }}$ line manager deviate from the workshop” (Lean coach).

- Ward 3: A 3-hour workshop was performed during which the group initiated mapping of the "Present State" of the selected value stream. "The physician sits back from the table emphasizing that she needs to do other things” (Lean coach). The $1^{\text {st }}$-line manager did not participate. After the first workshop the participants decided not to continue. Following this decision the $1^{\text {st }}$ line manager was interviewed. She stated: “... Decision to carry out VSM are not anchored among staff ...”. During a similar interview with the physician participating in the VSM workshop she claimed:

o “... I did not understand why they selected that flow..."

o “... we did not think we had major problems with that flow ...”.

o “... we decided not to continue the VSM process as we prioritized other activities ...”

Researcher note regarding all three wards: “In general poor/no knowledge about VSM among the participants in the workshops”. During the interview with the production developer at the hospital he assessed: “... We do not consider work environment issues when running the VSM process ...”.

\section{The Icelandic ward:}

The hospital had about 4900 employees and a turnover of about 290 million $€$ per year. In 2011 top management at the hospital decided to deploy Lean. The introduction of Lean was mainly based on support from McKinsey, an American global management consulting firm that focuses on solving issues of concern to senior management (http://en.wikipedia.org/wiki/McKinsey_\%26_Company). They had no clear focus on work 
environment issues that may result from introduction of Lean (researcher notes from workshops where Lean was introduced to employees at the hospital). However, they emphasized that no employees would become redundant due to Lean projects.

The investigated ward had two $1^{\text {st }}$ line managers. After 10 months and seven workshops the $1^{\text {st }}$ line managers decided not to fulfil this process. Initially, three employees participated in the workshops in addition to the Lean coach. Gradually all three members of the Lean team left due to maternity leave and going on part-time employment not allowing space for participation in the workshops. Routines for replacing these members were lacking. The Lean coach stated that “... the group members had limited connection to management”. One of the $1^{\text {st }}$ line managers stated that "... wrong people were also chosen for the Lean team ... an important occupational group was missing". The Lean team initiated implementation of proposals from their Action Plan but this process was interrupted when the Lean team disappeared. An additional reason was that the $1^{\text {st }}$ line managers were not pleased with the proposals: "You can say that the result of the Lean project has been destruction of the formal system but nothing good came instead. So chaos is the result of the project” and further “...I should have followed the project through and be encouraging and supportive of the process”. The other $1^{\text {st }}$ line manager said "Well, the problem with ... (the partial implementation of suggested change) is that no good alternative came instead, so we kind of went backwards, that was rather disappointing”, and further “... we should have been more involved in this project to give support...”.

In general, the Lean coach stated “... we have problems motivating the participants of the VSM group ...”. However, she perceived a facilitated VSM process at the investigated ErgoVSM ward (part of the Multicentre Study, Winkel et al 2012, see Introduction). Due to this, the Lean coach decided on her own initiative to include work environment aspects in the VSM processes performed at other wards not part of any research project. Positive effects on 
those VSM processes were reported back to the researchers from the Lean coach. She stated:

Generally, the work environment and how we can make it better has become a part of our Lean work. We always find something we can make better”.

The Danish wards:

The hospital had about 9500 employees and a turnover of about 830 million $€$ per year. In 2006 top management at the hospital decided to deploy Lean. Each year between 2006 and spring 2010 top management selected a number of wards to implement Lean (http://www.ouh.dk/wm231659). “It was top down, it was 'push’, and they (top management) wanted the clinical departments to work with Lean, ... top management selected the departments that should work with Lean ...” (Lean manager).

The results from the push approach were mixed and the Department for Operational Optimization (DOO) experienced that the selected wards did not take full ownership of the projects; “... the results were not sufficiently maintained” (Lean manager). This was partly explained by lack of time for Lean projects at the wards: “... (the) core task is indeed to treat patients, and the more projects that draw resources ... the harder it is to get time for the daily operations” (Lean manager).

During fall 2009 the DOO proposed a new Lean concept to top management of the hospital: "Focused Interventions” (Internal memo to top management October 12, 2009). This was implemented spring 2010. The purpose of “Focused Intervention” was to “improve operating efficiency in order to increase revenue and/or reduce costs within the existing framework” (Internal memo to management October 12, 2009). The "Focused Intervention” concept is essentially a pull approach that relies on the wards to request support for a focused and well defined change project.

At this time aspects of the work environment were handled by part of the HR 
department. However, the Lean Manager stated: “Typically they gathered people for a half to a full day workshop and talked about behaviour, rules and recognition..... But afterwards people ... (were) ... still faced with the day-to-day operations and nothing changed..., so you ... (were) ... back in the same old pattern”. Soon after, this part of the HR department was eliminated and DOO began to receive requests for help regarding aspects of the work environment such as stress-related issues. Due to this it was decided that the "Focused Intervention” concept, originally defined as a rationalization approach, should also consider these issues. Thus, a new practice evolved mixing Lean and work environment issues and this appeared to work better than the original HR-approach: "By using Lean and focus on patient flow we can reduce stress” (Lean Manager). The “Focused Intervention” projects were sometimes also used to comply with requests from the Work Environment Agency (http://www.ouh.dk/wm315043).

The "Focused Intervention” implies a series of workshops where the staff develops solutions to their problems facilitated by a Lean coach from DOO. The workshops generally includes a larger number of staff participants than usually recommended in the Lean literature (e.g. Jarebrant et al., 2015; indicating 5-8 participants); in six observed projects with 27 workshops an average of 10 people from each ward participated. In general, the participating staffs were now replaced at their shifts when running the workshops.

Following introduction of the "Focused Intervention" concept the motivation at the wards seemed to change. The Lean manager stated: “... the departments’ request ... your help ... to change anything in daily operations, and ... then you can also put a completely different pressure of expectations on them ...”. The DOO continued teaching Lean courses to the hospital staff and “... by 2015 approx. 4000 people have attended” (Lean manager).

\section{Discussion}


The results of this exploratory pilot study tentatively point to the facilitating effect on the VSM process of supplementing the VSM tool with work environment issues which are of immediate concern for the employees, 1st line manager support, well-established and broadly accepted VSM routines, involvement of the participants and allocating additional staff resources to the wards participating in the VSM workshops.

According to Haines et al. (2002) five dimensions of participative ergonomics seem to be particularly important: “involvement”, “decision-making”, “remit”, “mix of participants” and "role of ergonomics specialist". The VSM processes differed considerably between the hospitals regarding the three first mentioned dimensions. In Sweden the participants in the workshops only mapped present and future state, but were neither involved in developing the Action Plans nor making decisions regarding implementation. The activities that fell within participants’ remit did not include the complete improvement process; problem identification, solution generation, implementation and evaluation as described by Haines et al (2002). In all three countries the top-down (“push”) approach appeared to work poorly and allowed for little involvement. When the Danish hospital changed to a bottom-up (“pull”) approach the motivation seemed to increase. A bottom-up approach is presumed to increase empowerment (e.g. Westgaard and Winkel 1997, 2011), which is related to the factors 'decision-making' and 'involvement' (Haines et al., 2002).

In general, the VSM change methodology worked poorly at the Swedish and Icelandic hospitals while the Danish hospital, after an initial 4-year period, managed to develop and improve their processes. Previous research on participatory ergonomics interventions has shown the significance of e.g. management engagement, resource availability (time, material and personnel) and proper training in order to obtain impact (e.g. Eerd er al., 2010; Haines et al., 2010; Punnett et al., 2013; Rivilis et al., 2008). These issues also seem to be important in the present investigated change processes aiming at waste reduction (i.e. rationalisation). 
Management engagement ( $1^{\text {st }}$ line managers) was poor at both the Swedish and Icelandic hospitals but strong at the Danish hospitals where $1^{\text {st }}$ line managers participated in VSM workshops. $1^{\text {st }}$ line manager participation therefore seems to be an additional factor to ensure the success of VSM workshops.

Resource availability was considered at the Danish hospital by replacing staffs at their shift when they participated in the workshops and also by allowing a larger number of participants in the workshops than usually recommended (Jarebrant et al, 2015). Lack of time for participation in the workshops was assessed as a problem in Sweden and Iceland, and initially also in Denmark. The Danish hospital invested in comprehensive Lean training of the employees in contrast to the two other hospitals. Allocation of sufficient resources for these purposes may therefore contribute to the success of VSM workshops.

At the Icelandic hospital they had problems motivating the VSM groups and the fact that the Lean coach by herself started to include work environment issues in the VSM processes at the hospital illustrates the potential of including issues of immediate significance for the individual employee. The same experience was reported at the Danish hospital when they changed strategy 2010 allowing work environment issues to become an integrated part of the ordinary VSM processes and Action Plans.

At the Icelandic hospital Lean and VSM had recently been introduced. Thus the employees had not been trained and had low motivation to engage in the VSM processes. Using a computer-based excel spreadsheet rather that the well-established "paper-and-pen” procedure (see Introduction) seemed to inhibit participation. At the Swedish hospital they had changed the VSM procedure by excluding the workshop participants from assessing their own Action Plan. In Denmark, both a clear general Lean organisation and a clear VSM process were developed. This was supported by comprehensive training of the employees thus allowing the workshops to run efficiently. The procedures, prerequisites and aims were 
broadly accepted by the employees at the hospital. Altogether, this points towards the significance of well-established and broadly rooted routines as an additional issue to obtain successful VSM processes.

As part of our Multicentre Study (Winkel et al 2012) we have communicated with several other Nordic Hospitals in addition to those investigated. At several of these hospitals Lean has become a buzzword with a strong negative association among employees. At one of the hospitals the head of the Lean program reported that they had stopped using the word Lean: "We have at present no focused efforts at Lean in the hospital. We have chosen to use the term Total Quality in our management system” (Personal Communication). Similar reports have also been received from 2 other large Nordic hospitals. Lean seems to have developed into a “dirty word”, in particular among the physicians. Unfortunately, and by obvious reasons, unsuccessful introductions of Lean are poorly analysed and published in the scientific literature. The negative associations to Lean are presumably due to the work intensification that often becomes the long-term result following introduction of Lean (Landsbergis et al, 1999). On this background, the present results may serve as a wake-up call, not at least at the many hospitals that now introduce Lean and VSM. In addition, it may also provide ideas for further research aiming at improved understanding of change processes in healthcare towards increased “organizational sustainability”, i.e. joint consideration of competitive performance and working conditions in a long term perspective (Westgaard and Winkel 2011).

The successful change in the Lean procedure at the investigated Danish hospital after year 2010 was related to issues facilitating the change process while the final aim of the process was unchanged; i.e. to “...improve operating efficiency in order to increase revenue and/or reduce costs within the existing framework” (see Results). This was also emphasized by the Lean manager (“... then you can also put a completely different pressure of 
expectations on them”). It may be questioned if a facilitated change methodology is sufficient to increase organizational sustainability when the overall aim is revenue/costs/waste reduction only, given the strong relationship between waste reduction and work intensification (Jonker et al., 2011; Jonker et al., 2013; Kazmierczak et al., 2005; Ostenvik et al., 2008; Palmerud et al., 2012; Westgaard and Winkel, 2011).

Several initiatives on integration of production system performance and the work environment towards increased sustainability have been discussed from a theoretical point of view (Holden et al., 2008; Zink et al., 2008; Winkel and Westgaard, 1996) and a limited number of case studies have been carried out in industry (e.g. Bao et al., 1996; Kadefors et al., 1996; Neumann et al., 2009). Within healthcare we have not been able to identify such initiatives. During recent years the investigated Swedish hospital initiated praiseworthy projects aiming at integrating work environment issues into their primary development efforts in order to increase revenue and reduce costs (Jonson et al., 2013). However, this has apparently not implied any changes in their VSM procedures as observed in the present cases. We are, however, aware of several running Nordic research projects on this issue.

VSM is today a widely used tool in industry as well as in healthcare. The aim is to catalyse Organizational Change. Within the prevalent Organizational Change Discourse, 'Change Management' is a relatively recent concept that has received a marked interest in the business literature (By et al., 2014). Theories and approaches to 'Change management' mostly lack empirical evidence (By et al., 2005). It has been defined as "the process of continually renewing an organization's direction, structure, and capabilities to serve the ever-changing needs of external and internal customers” (Moran and Brightman, 2001). It is suggested that the present type of results may contribute to the scarce empirical basis of 'Change Management' towards theories and models for increased organizational sustainability. 


\section{Conclusion}

The present exploratory case study points to the potential facilitating effect on change processes in healthcare by

(1) Emphasizing involvement and decision-making among the participants of the VSM workshops (cf. Haines et al., 2002)

(2) $1^{\text {st }}$ line manager support and engagement

(3) Allocating sufficient resources for replacing staff at their shift when participating in VSM workshops and for comprehensive Lean training of the employees

(4) Supplementing the VSM tool with work environment issues of immediate concern for the employees

(5) Well-established and broadly accepted VSM routines

Each of these conclusions needs to be further investigated to properly understand their quantitative significance, possible causal relationships and potential pitfalls.

\section{Acknowledgements}

This study has received financial support from the Danish Working Environment Research Fund (\#46-2010-09), the healthcare authority in the county of Västra Götaland, Skaraborg hospital, Sweden (\#SkaS 00203-2011) and the University of Iceland Research Fund (\#HI1209090106).

The authors thank the Lean organizations at the participating hospitals in Denmark, Iceland and Sweden as well as the employees at the investigated wards.

\section{References}

Bao, S., Mathiassen, S. E., Winkel, J. (1996) Ergonomic effects of a management-based 
rationalization in assembly work - a case study. Applied Ergonomics, 27, 89-99

Brännmark, M., Langstrand, J., Johansson, S., Halvarsson, A., Abrahamsson, L., Winkel, J.

(2012) Researching Lean: Methodological implications of loose definitions. Journal:

Quality Innovation Prosperity, XVI/2, pp 35-48

By, R. T. (2005) Organisational Change Management: A Critical Review. Journal of Change Management. 5(4), pp. 369-380

By, R.T., Oswick, C. and Burnes, B. (2014) Looking Back and Looking Forward: Some Reflections on Journal Developments and Trends in Organizational Change Discourse. Journal of Change Management, 14 (1), pp. 1-7

Eerd, D. van, Cole, D., Irvin, E., Mahood, Q., Keown, K., Theberge, N., Village, J., Vincent, M. St., Cullen, K. (2010) Process and implementation of participatory ergonomic interventions: a systematic review. Ergonomics, 53(10), 1153-1166

Härenstam, A., Bejerot, E., Johansson, K., Leijon, O., Schéele, P. (2000) “Mager och god” eller ”Lean and mean”? Samband mellan organisationsförändringar och arbetsförhållanden. In: Barklöf, K. (Ed.) ”Smärtgränsen? En antologi om hälsokonsekvenser i magra organisationer”. Rådet för arbetslivsforskning. Ord och Vetande AB, Uppsala. 134 pages. ISBN: 91-88530-88-4. (In Swedish)

Haines, H., Wilson, J.R., Koningsveld, E. (2002) Validating a framework for Participatory ergonomics (the PEF). Ergonomics 45, 309-327

Holden, R.J., Or, C.K.L., Alper, S.J., Rivera, A.J., Karsh, B.T., (2008). A change management framework for macroergonomic field research. Applied Ergonomics 39, $459-474$

Jarebrant, C., Birgisdóttir, B. D., Dudas, K., Edwards, K., Gunnarsdóttir, S., Harlin, U., Johansson Hanse, J., Winkel, J. (2014) Development of a tool for integrating Value Stream Mapping and ergonomics in healthcare - A Nordic Multicenter study. The 7th 
Nordic Working Life Conference: “Threats and Possibilities Facing Nordic Working Life”, PP 123-124. University of Gothenburg, Sweden, June 11-13 2014. Book of Abstracts, ISBN 978-91-981195-5-8, URI http://hdl.handle.net/2077/35379

Jarebrant, C., Winkel, J., Johansson Hanse, J., Mathiassen, S. E., and Öjmertz, B. (2015) A tool for integrating Value Stream Mapping and ergonomics in manufacturing. Human Factors and Ergonomics in Manufacturing \& Service Industries. DOI: 10.1002/hfm.20622

Jonker, D., Rolander, B., Balogh, I., Sandsjö, L., Ekberg, K., and Winkel, J. (2011) Mechanical exposure among general practice dentists in Sweden and possible implications of rationalization. Ergonomics, 54, 953-60

Jonker, D., Rolander, B., Balogh, I., Sandsjö, L., Ekberg, K., and Winkel, J. (2013) Rationalisation in public dental care - impact on clinical work tasks and mechanical exposure for dentists - a prospective study. Ergonomics, 56(2), 303-313

Jonson, L. C., Lepik, A., Sundström, L. (2013) Projekt OVIEL. Utvärderingsrapport 201304-26. Västra Götalandsregionen, Skaraborgs sjukhus. 27 pages (In Swedish)

Kadefors, R., Engstrom, T., Petzall, J., Sundstrom, L. (1996) Ergonomics in parallelized car assembly: a case study, with reference also to productivity aspects. Applied Ergonomics 27, $101-110$

Kazmierczak, K., Mathiassen, S. E., Forsman, M., and Winkel, J. (2005) An integrated analysis of ergonomics and time consumption in Swedish 'craft-type' car disassembly. Applied Ergonomics 36, 263-273

Keyte, B., Locher, D. (2004) The Complete Lean Enterprise. Value Stream Mapping for Administrative and Office Processes. Productivity Press, New York

Landsbergis, P.A., Cahill, J., Schnall, P. (1999) The impact of lean production and related new systems of work organization on worker health. Journal of Occupational Health 
Psychology 4, 108-130

Lifvergren, S. (2010) Alla dessa begrepp - vad menar vi egentligen? Pulsen, June, page 2. (In Swedish)

Liker, J. (2004) The Toyota way: 14 management principles from the world's greatest manufacturer. New York, NY: McGraw-Hill

Neumann, W. P., Ekman, M., Winkel, J. (2009) Integrating ergonomics into production system development - The Volvo Powertrain Case. Applied Ergonomics, 40, 527-537

Moran, J. W. and Brightman, B. K. (2001) Leading organizational change, Career Development International, 6(2), pp. 111-118

Ostensvik, T., Veiersted, K. B., Nilsen, P., Cuchet, E., Johansson Hanse, J., Carlzon, C. and Winkel, J. (2008) A search for risk factors of upper extremity disorders among forest machine operators in France and Norway. International journal of industrial ergonomics, 38, 1017-1027

Palmerud, G., Forsman, M., Neumann, P. W., and Winkel, J. (2012) Mechanical exposure implications of rationalization: a comparison of two flow strategies in a Swedish manufacturing plant. Applied Ergonomics, 43, 1110-1121

Punnett, L., Warren, N., Henning, R., Nobrega, S., Cherniack, M. and The CPH-NEW Research Team. (2013) Participatory Ergonomics as a model for integrated programs to prevent chronic disease. Journal of Occupational and Environmental Medicine, 55(12), Suppl.

Rivilis, I., Van Eerd, D., Cullen, K., Cole, D. C., Irvin, E., Tyson, J., and Mahood, Q. (2008) Effectiveness of participatory ergonomic interventions on health outcomes: A systematic review. Applied Ergonomics, 39, 342-358

Westgaard, R. H., and Winkel, J. (1997) Ergonomic intervention research for improved musculoskeletal health: A critical review. International Journal of Industrial Ergonomics, 
20, 463-500

Westgaard, R.H., and Winkel, J. (2011) Occupational musculoskeletal and mental health: Significance of rationalization and opportunities to create sustainable production systems: A systematic review. Applied Ergonomics, 42, 261-296

Winkel, J., Birgisdóttir, B. D., Dudas, K., Edwards, K., Gunnarsdóttir, S., Jarebrant, C., Johansson Hanse, J. (2012) A Nordic work environment complement to Value Stream Mapping (VSM) for sustainable patient flows at hospitals - A NOVO Multicenter study. 6th NOVO Symposium: Sustainable Health Care: Continuous Improvement of Processes and Systems. Karolinska Institute, Stockholm Sweden. November 15-16, 2012, pp 58-59. ISBN: 978-91-637-2380-3

Winkel, J., Westgaard, R. H. (1996) A model for solving work related musculoskeletal problems in a profitable way. Applied Ergonomics, 27, 71-77

Zink, K.J., Steimle, U., and Schroder, D. (2008) Comprehensive change management concepts - development of a participatory approach. Applied Ergonomics 39, 527-538

Keywords. Change Management, Change Process, Intervention, Lean, Organizational change, Patient value stream, Production Ergonomics, Sustainable production system, Tool, Value Stream Mapping. 